\title{
ESPECIES ARBÓREAS DE LAS FAMILIAS EUPHORBIACEAE, PITTOSPORACEAE Y SALICACEAE SON INFECTADAS POR 'CA. PHYTOPLASMA FRAXINI' $Y$ 'CA. PHYTOPLASMA ASTERIS' EN INFECCIONES MIXTAS EN BOGOTÁ, COLOMBIA
}

Fecha de recepción: 4 de octubre de 2013 • Fecha de aceptación: 15 de noviembre de 2013

TREE SPECIES OF EUPHORBIACEAE, PITTOSPORACEAE AND SALICACEAE FAMILIES ARE INFECTED BY 'CA. PHYTOPLASMA FRAXINI' AND 'CA. PHYTOPLASMA ASTERIS' IN MIXED INFECTIONS IN BOGOTA, COLOMBIA

Laura M. Perilla-Henao' • Liliana Franco-Lara ${ }^{2,3}$

\section{RESUMEN}

La presencia de fitoplasmas del grupo $16 \mathrm{Srl}$ ('Ca. Phytoplasma asteris') fue reportada en Croton spp. (Euphorbiaceae), Pittosporum undulatum (Pittosporaceae) y Populus nigra (Salicaceae), en Bogotá. En este trabajo se reporta la existencia adicional de fitoplasmas del grupo 16SrVII 'Ca. Phytoplasma fraxini' en estas mismas especies de árboles ornamentales, por técnicas moleculares como PCR anidada, RFLP y secuenciación del gen 16SrRNA. Los resultados muestran la existencia de un complejo de fitoplasmas de los grupos $16 \mathrm{Srl}$ y $16 \mathrm{SrVII}$ que se asocian con síntomas como deformación general de la corona, ramas en copo, amarillamiento, elongación anormal de brotes apicales, escobas de bruja y rebrotación epicórmica que afectan el estado de sanidad de los árboles. En diciembre de 2013 la prevalencia sintomática en Croton spp., P. undulatum y P. nigra y se estimó en 36\%, 93\% y 85\% respectivamente. Este trabajo presenta evidencia de que plantas de familias diferentes a Oleaceae que son susceptibles a fitoplasmas del grupo $16 \mathrm{SrVII}$ y que en este caso se encuentran en infecciones mixtas con fitoplasmas del grupo 16Srl. Se presentan evidencias de una enfermedad emergente de alta prevalencia en estas especies de árboles han pasado desapercibidas hasta la fecha, pero suponen un riesgo para la supervivencia de los árboles urbanos en Bogotá.

Palabras clave: Croton spp, Pittosporum undulatum, Populus nigra, árboles urbanos, gen 16srRNA, enfermedad emergente.

Joven Investigadora Universidad Militar Nueva Granada, Km 2 via Cajicá-Zipaquirá, Colombia

2 Docente Facultad de Ciencias Básicas y Aplicadas, Universidad Militar Nueva Granda, Km 2 via Cajicá-Zipaquirá, Colombia.

3 Autor para correspondencia: liliana.franco@unimilitar.edu.co 


\section{ABSTRACT}

The Presence of phytoplasmas of group 1Srl ('Ca. asteris') was reported in Croton spp. (Euphorbiaceae), Pittosporum undulatum (Pittosporaceae) and Populus nigra (Salicaceae) in Bogotá. This work reports the additional existence of phytoplasmas of the group 16SrVII ('Ca. Phytoplasma fraxini') in the same species of ornamental trees, by molecular techniques such as nested PCR, RFLP and sequencing of the 16SrRNA gene. These results show the existence of a complex of phytoplasmas of groups $16 \mathrm{Srl}$ and $16 \mathrm{SrVII}$ that is associated to symptoms such as general deformation of the crown, tufted foliage, yellowing, abnormal elongation of apical shoots, witches'-brooms and epicormic shoots that affect the health status of the trees. In December 2013 the symptomatic prevalence for Croton spp, P. nigra and P. undulatum was estimated in 36\%, 93\% and $85 \%$ respectively. This work presents evidence in plants families different from Oleaceae that are susceptible to phytoplasmas of group $16 \mathrm{SrVII}$ and that in this case are found in mixed infections with phytoplasmas of group $16 \mathrm{Srl}$. We present evidence of an emergent disease of high prevalence in these tree species that has passed unnoticed, but that represents a risk for the survival of the urban trees in Bogota.

Keywords: Croton spp, Pittosporum undulatum, Populus nigra, urban trees, 16srRNA gene, emergent disease.

\section{INTRODUCCIÓN}

Los fitoplasmas son bacterias pleomórficas, sin pared celular, de la clase Mollicutes, especializados en colonizar el floema de las plantas que infectan y transmitidos por vectores del suborden Auchenorrhyncha (Hemiptera). Los fitoplasmas comprenden un grupo monofilético altamente diverso (Lee et al., 2000; Weintraub y Beandland, 2006; Wei et al., 2007; Bertaccini y Duduk, 2009) y se diferencian de otros mollicutes en que son difícilmente cultivables (Contaldo et al., 2012). Su detección y clasificación se basa principalmente en el análisis de una región conservada del gen 16SrDNA (Gundersen et al., 1994; Sears and Kirkpatrick, 1994; Wei et al., 2007; Zhao et al., 2010) así como su detección e identificación depende de herramientas moleculares como PCR, PCR anidado, RFLP y secuenciación, principalmente de esta región (Lee et al., 1994; Lee et al., 1998; Seemüller et al., 1994; Seemüller et al., 1998). En la actualidad existen dos sistemas paralelos de clasificación, ambos basados en el gen 16SrDNA. El primero establece los grupos a partir de patrones de corte de 17 enzimas de restricción en 32 grupos 16Sr RNA (Nejat et al., 2013). A su vez, cada grupo puede estar subdividido en subgrupos cuya determinación se complementa usando secuencias de otros genes como rp (proteínas ribosomales), secY, tuf y la región intergénica espaciadora 16S-23SrDNA, entre otros (Smart et al., 1996; Martini et al., 2007; Lee et al., 2006). El segundo sistema de clasificación es el taxonómico formal, que emplea el término 'Candidatus' para referirse a especies bacterianas no cultivables. Se llama 'Candidatus (Ca.) Phytoplasma' a una cepa portadora de una única secuencia de $<1200$ pb del gen 16SrDNA. Una cepa se considera una nueva especie si su secuencia 16SrDNA presenta una similitud menor a $97.5 \%$ respecto a secuencias previamente descritas (IRPCM, 2004). Se han propuesto 33 especies dentro del género $\mathrm{Ca}$. Phytoplasma (Bertaccini y Duduk, 2009). 
Los fitoplasmas se asocian a muchas enfermedades que producen amarillamiento del follaje y generan cambios morfológicos en la estructura de las plantas infectadas que dependen del tipo y edad de la planta hospedera, de la cepa de fitoplasma que coloniza, de la etapa de la enfermedad y de las condiciones ambientales (Lee et al., 2000). Los síntomas más comunes incluyen la formación de escobas de bruja, filodia (metamorfosis de órganos florales en hojas), virescencia (coloración verde de pétalos), elongación de tallos, formación de brotes en copos, enrojecimiento de hojas y tallos, enanismo, arrosetamiento de las ramas, proliferación de brotes, amarillamiento, necrosis del floema y decaimiento 2008; Bertaccini y Du(Lee et al., 2000; Hogenhout et al., duk, 2009). En plantas leñosas se pueden observar también síntomas como amarillamiento, enrojecimiento, hojas pequeñas, hojas entorchadas, aclaramiento de venas, alargamiento de venas, necrosis de venas, defoliación prematura, coloración de otoño prematura, frutos pequeños, crecimiento terminal pobre, follaje disperso, muerte regresiva ("dieback"), atrofia y decaimiento (Lee et al., 2000; Sinclair and Griffiths, 1994; Bertaccini y Duduk, 2009). Las plantas infectadas con fitoplasmas presentan cambios bioquímicos como el bloqueo en el transporte a través del floema, cambios en la translocación de fotosintatos, reducción en la tasa fotosintética, alteración del metabolismo secundario y perturbación del balance hormonal de las plantas (Christensen et al., 2005). Las desviaciones de la normalidad en la morfología de las especies estudiadas pueden atribuirse a desórdenes de los reguladores de crecimiento que se cree que son causados por los fitoplasmas. Existe poco conocimiento sobre los mecanismos de patogenicidad de los fitoplasmas, pero algunos resultados recientes indican que estos patógenos secretan en sus huéspedes efectores que afectan el metabolismo de las auxinas (Lee et al., 2000; Christensen et al., 2005 Bertaccini y Duduk, 2009).
Hasta comienzos de la década de 2000, se pensaba que los fitoplasmas del grupo 16SrVII (subgrupo 16SrVII-A) estaban restringidos a los géneros Fraxinus y Syringa de la familia Oleaceae exclusivamente en Norte América (Sinclair et al., 1996; Griffiths et al., 1999). El primer reporte de fitoplasmas $16 \mathrm{SrVII}-\mathrm{A}$ fuera de Norte América fue hecho para Fraxinus uhdei en Colombia (Griffiths et al., 2001; Filgueira et al., 2004; Franco-Lara y Filgueira, 2005). Posteriormente, fitoplasmas del subgrupo 16SrVII-A fueron reportados en duraznero en Canadá (Zunnoon-Khan et al., 2010), vides en Chile (Longone et al., 2011) y en el arbusto Ugni molinae (Myrtacea) y en la herbácea Paeonia lactiflora (Paenaciae) en Chile (Arismendi et al., 2011). Fitoplasmas de los subgrupos 16SrVII-B han sido reportados en Erigeron sp. en Brasil (Barros et al., 2002) y 16SrVII-C en alfalfa en Argentina (Conci et al., 2005). Fuera de América hay por lo menos un reporte de la presencia del grupo 16SrVII Hypericum perforatum en Europa (Bruni et al., 2005).

Generalmente, las enfermedades asociadas a fitoplasmas se asocian a un solo grupo de fitoplasmas, pero infecciones en las cuales están presentes varios grupos de fitoplasmas simultáneamente han sido descritas en algunos patosistemas. Por ejemplo en Australia tres grupos de fitoplasmas se encuentran infectando plantas de vid: 'Ca. Phytoplasma australiense' (CPA), tomato big bud phytoplasma (TBB) y Buckland Valley grapevine yellows phytoplasma (BVGY) (Gibb et al., 1999; Constable et al., 2002). Por otra parte, los grupos16SrV y $16 \mathrm{SI}$ se encuentran infectando vides en Italia (Alma et al., 1996), produciendo síntomas similares a los descritos en Australia. Potato purple top wilt (PPT) es una enfermedad devastadora que ocurre en varias regiones de Norte América y México donde al menos cuatro fitoplasmas de cepas distintas (16Srl, $16 \mathrm{Srll}$ and $16 \mathrm{SrVI}$ and XII) se han asociado con esta enfermedad (Leyva-López et al., 2002; Lee et al., 2006). Por otro lado, en Texas, Estados Unidos en cultivos como zanahoria, cebolla, perejil, eneldo y en varias 
arvenses, en se encontraron fitoplasmas de los subgrupos $16 \mathrm{Srl}-\mathrm{A}$ y $16 \mathrm{Srl}-\mathrm{B}$ en combinaciones variadas y en algunos casos co-infectando la misma planta (Lee et al., 2003). En todos estos casos, el rango de severidad de los síntomas de las plantas afectadas era variable y no asociado con un grupo de fitoplasmas en particular. Además, las plantas hospederas infectadas por complejos de dos o más fitoplasmas no presentaban síntomas únicos ni más severos en comparación con las plantas infectadas con un solo fitoplasma (Gibb et al., 1999; Constable et al., 2002; De La Rue et al, 2001; Lee et al., 2006). Hasta donde sabemos, no se han reportado infecciones mixtas que involucran a fitoplasmas del grupo 16SrVII.

A inicios de la década de 2000, se demostró que los urapanes (Fraxinus uhdei, Oleaceae) de Bogotá presentaban síntomas como amarillamiento, defoliación, presencia de ramas muertas, muerte de ramas de la punta a la parte basal (dieback), decaimiento (decline), ramificación con hábito delicuescente, hojas pequeñas, ramas con hojas apretadas formando copos y rebrotación epicórmica, que se atribuyeron a fitoplasmas tipo Ash Yellows (Grupo 16SrVII) (Griffiths et al., 2001; Filgueira et al., 2004; Franco-Lara y Filgueira, 2005). El grupo de fitoplasmas 16 SrVII también se asocia a las enfermedades "Ash Yellows" y "Lilac Witches'-broom" que afectan plantas de los géneros Fraxinus y Syringa en Norte América (Sinclair et al., 1996; Griffiths et al., 1999). Cuando se hicieron estos reportes se consideraba que la fitoplasmosis de los de Urapanes de Bogotá era una enfermedad exótica que solo afectaba esta especie de árboles. Sin embargo, recientemente se ha demostrado la presencia de infecciones mixtas de fitoplasmas de los grupos 16Srl, $16 \mathrm{SrV}, 16 \mathrm{SrVII}$ y $16 \mathrm{SrXII}$ en liquidámbares sintomáticos de Bogotá (Liquidambar styraciflua, Hamamelidaceae) (Franco-Lara et al., 2010).

En árboles urbanos de Bogotá como sangregado (Croton spp.), jazmín del cabo (Pittosporum undulatum) y chopo Populus nigra la presencia de síntomas como deformación de las coronas, amarillamiento, defoliación, brotes epicórmicos, ramas en copo, ramificación delicuescente, etc. se ha asociado a la infección por fitoplasmas de grupo 16Srl (Perilla et al., 2012, Franco-Lara, 2013). El presente trabajo incluye análisis moleculares adicionales por RFLP y secuenciación de muestras de árboles sintomáticos de tres especies no oleáceas, en los cuales se detecta la presencia de fitoplasmas del grupo $16 \mathrm{SrVII}$ en infecciones mixtas con el grupo $16 \mathrm{Srl}$.

\section{MATERIALES Y MÉTODOS}

\section{Material vegetal y estimación de la prevalencia}

Este estudio se llevó a cabo en la ciudad de Bogotá D. C., Colombia, (Latitud Norte 4³5'56"57 y Longitud Oeste $74^{\circ} 04^{\prime} 51^{\prime \prime} 30$ ) a $2.630 \mathrm{~m}$ sobre el nivel del mar. En diferentes fechas entre 2008 y 2011 se

El presente trabajo incluye análisis moleculares adicionales por RFLP y secuenciación de muestras de árboles sintomáticos de tres especies no oleáceas, en los cuales se detecta la presencia de fitoplasmas del grupo $16 \mathrm{SrVII}$ en infecciones mixtas con el grupo $16 \mathrm{Srl}$. 
tomaron muestras de hojas y ramas jóvenes, 6 individuos de Croton sp., 5 de P. undulatum y 4 de P. nigra. Se seleccionaron árboles que presentaban deformaciones de la corona y la presencia de síntomas para cada individuo se reportó registrando su presencia a partir de una lista de síntomas que ocurren en árboles infectados con fitoplasmas (Sinclair y Griffiths, 1994; Sinclair et al., 1996; Boa, 2003). La lista de síntomas incluyó: deformación general de la corona, ramas en copo, entrenudos delicuescentes, pigmentación púrpura anormal de hojas y corona, amarillamiento, elongación anormal de brotes apicales, escobas de bruja, rebrotación, hojas pequeñas, rebrotación epicórmica, ramas muertas, virescencia y filodia.

La prevalencia se estimó como el número de árboles al azar (diferentes a los árboles en los cuales se detectaron los fitoplasmas) con más de tres síntomas sobre el total de árboles visitados en diciembre de 2013, en 6 localidades diferentes de Bogotá. Se evaluaron 33 árboles de Croton spp., 15 de P. nigra y 20 de $P$. undulatum. Diferentes números de muestra reflejan los diferentes tamaños poblacionales de estas especies en los lugares visitados.

\section{Extracción de ADN}

Para la extracción de ADN, las hojas y ramas se limpiaron superficialmente con agua y jabón, y se desinfectaron superficialmente con etanol al 70\%. El tejido fresco correspondiente a los haces vasculares se separó de la médula y la corteza, y se almacenó a $-70^{\circ} \mathrm{C}$. Para las extracciones se utilizó el método de Prince et al. (1993) partiendo de $1 \mathrm{~g}$ de tejido proveniente de los haces vasculares, previamente macerado en nitrógeno líquido. El ADN extraído se resuspendió en buffer TE y el ADN se almacenó a $-20^{\circ} \mathrm{C}$.

\section{Amplificación por PCR anidada}

Con el objetivo de verificar la ausencia de sustancias inhibidoras de la PCR en los extractos de ADN vegetal, estos se usaron como molde en reacciones de PCR estándar (temperatura de alineación de $53^{\circ}$ C), con los iniciadores rpsF (5'- GTGGTAGAAAGCAACGTGCGACTT -3') y rpsR2 (5'-TGCGGATCGAACATCAATTGCAAC -3') (Oxelman et al., 1997) que amplifican el intrón rps16 del genoma de cloroplasto. Los extractos libres de inhibidores generaban un producto de $800 \mathrm{pb}$. Cuando no había amplificación, se realizaba un paso adicional de extracción median-

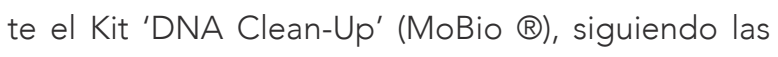
instrucciones de la casa comercial.

Para la detección de fitoplasmas, los extractos de ADN se amplificaron con iniciadores para el gen $16 \mathrm{~S}$ rRNA, en reacciones de PCR anidadas. La reacción primaria se realizó con los iniciadores P1A/P7A (Lee

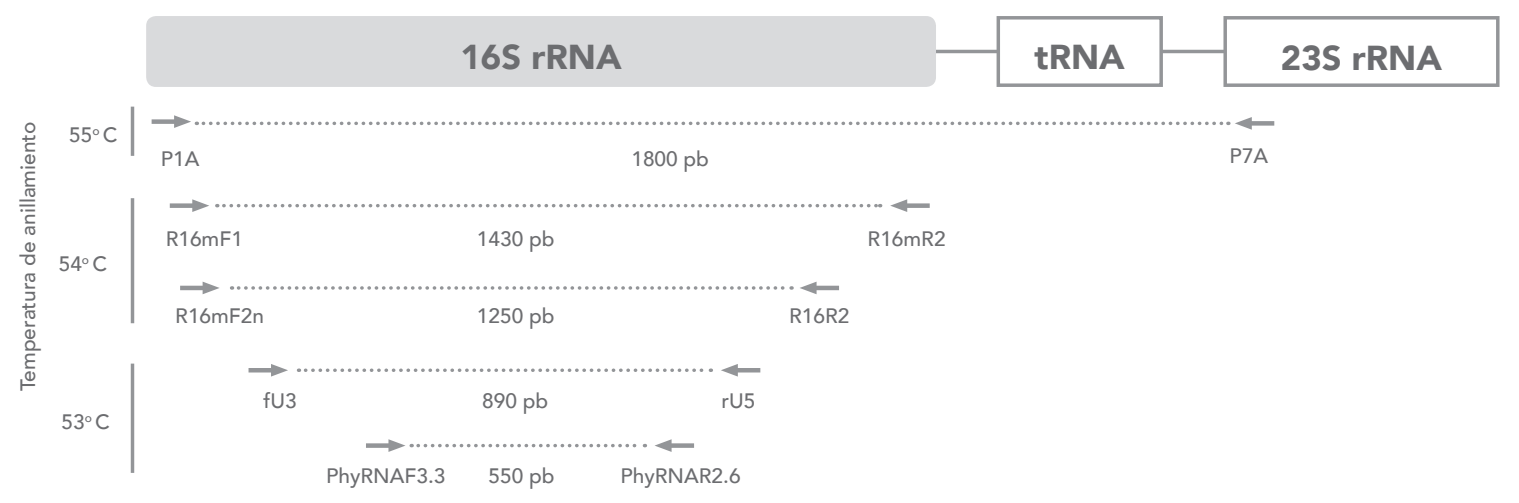

Figura 1. Ubicación de los iniciadores en el gen 16SrRNA usados para la detección de fitoplasmas por PCR anidada y temperatura de Anillamiento de los diferentes pares de iniciadores. 
et al., 2004) y posteriormente se realizaron una o dos reacciones de PCR anidadas consecutivas usando los pares de iniciadores R16mF2/R16mR1 o R16F2n/ R16R2 (Gundersen y Lee, 1996) en la primera anidada y posteriormente fU5/rU3 (Seemüller et al., 1994) o PhyrRNAF3.3/ PhyrRNAR2.6 (5'- AATAGTGGAAAAACTATC-3' y 5'- TTTCTATAACTTTGCAGA-3' respectivamente) en la segunda $\mathrm{PCR}$ anidada (Figura 1). Las reacciones de PCR se llevaron a volumen final de $15 \mu \mathrm{l}$, con 0,05 U/ $\mu \mathrm{L}$ de Taq polimerasa (Bioline $\left(\mathbb{B}_{)}\right.$, buffer de la enzima 1X, $1.5 \mathrm{mM}$ de $\mathrm{MgCl}$, 0,2mM de dNTPs (Bioline $\left.{ }^{\circledR}\right), 0.2 \mu \mathrm{M}$ de cada iniciador y 20 50 ng de ADN. En el caso de reacciones anidadas, el producto de la reacción primaria se diluyó 1:20 en agua y $2 \mu \mathrm{L}$ de la dilución se usaron como molde. El perfil térmico usado fue: denaturación por $10 \mathrm{~min}$ a $94^{\circ} \mathrm{C}, 35$ ciclos de denaturación a $94^{\circ} \mathrm{C}, 1 \mathrm{~min}$ alineamiento de los iniciadores dependiendo del par de iniciadores (Tabla 1), 2 min extensión a $72^{\circ} \mathrm{C}$ y un paso final de extensión por $10 \mathrm{~min}$ a $72^{\circ} \mathrm{C}$. Los productos de PCR se separaron por electroforesis estándar en gel de agarosa al $1 \%$ y se tiñeron con bromuro de etidio. Como controles positivos para PCR se usaron extractos de ADN de varios fitoplasmas generosamente donados por el Dr. Nigel Harrison (Universidad de Florida, USA) y la Dra. Assunta Bertaccini (Universidad de Boloña, Italia). Amplicones obtenidos con diferentes combinaciones de iniciadores en PCR anidada se enviaron a secuenciar o se analizaron por RFLP

\section{RFLP (Restriction Frangment Length Polymorphism)}

Amplicones seleccionados obtenidos con los iniciadores R16F2n/R16R2 se digirieron con las enzimas de restricción Alul, Rsal o Msel (New England Biolabs $\left.{ }^{\circledR}\right)$. En cada caso se prepararon reacciones a volumen final $20 \mu \mathrm{L}$ con el buffer recomendado por el fabricante a una concentración final $1 \mathrm{X}$ y 0,05 $\mathrm{U} / \mu \mathrm{L}$ de enzima, usando entre 5 y $7 \mu \mathrm{L}$ del producto de PCR. Todas las reacciones se incubaron durante $16 \mathrm{~h}$ a $37{ }^{\circ} \mathrm{C}$. Los productos de la reacción de digestión se separaron en gel de agarosa al 3 o 3.5\% en buffer TBE $1 X$ y se visualizaron con tinción de bromuro de etidio y radiación UV.

\section{Análisis de secuencias}

Amplicones seleccionados se purificaron del gel de agarosa con el Kit 'PCR Clean-up' (MoBio) y se enviaron a secuenciar en dos direcciones a Macrogen ${ }^{\circledR}$, Corea. Las secuencias obtenidas se compararon mediante nBLAST (Basic Local Aligment Search Tool) (Altschul et al., 1990) con la base de datos GenBank y se verificaron manualmente con Chromas Lite 2.1.1 (Technelysium). Las secuencias se alinearon con su complemento reverso para producir secuencias consenso. Las secuencias se alinearon usando CLUSTALW (BioEdit versión 7.1.3) con secuencias de cepas representativas de diferentes grupos de fitoplasmas y de fitoplasmas reportados en Colombia. Posteriormente se construyeron dendogramas en MEGA versión 5 (Tamura et al., 2011) usando el algoritmo de distancia Neighbor-Joining y con un valor de 'boostrap' de 1000 réplicas. El software iPhyClassifier (Zhao et al., 2009) se utilizó para determinar los coeficientes de similitud de los patrones de restricción con 17 enzimas de restricción, que permiten la determinación de subgrupos 16 SrRNA.

\section{RESULTADOS}

\section{Síntomas de árboles y prevalencia}

Los árboles de los cuales se tomaron muestras para este trabajo mostraban cambios en la estructura de la corona o modificaciones sustanciales de los patrones de crecimiento normal. Los síntomas característicos de cada especie se resumen en la tabla 1. En todos los casos, los árboles presentaban al menos tres síntomas asociados con fitoplasmosis. 
254 UNIVERSIDAD MILITAR NUEVA GRANADA

Tabla 1. Síntomas observados en árboles de diferentes especies

\begin{tabular}{lccc}
\hline \multicolumn{1}{c}{ Síntomas } & Croton spp. & P. nigra & P. undulatum \\
\hline Deformación general de la corona & & $X$ & $X$ \\
\hline Brotes epicórmicos & $X$ & $X$ & $X$ \\
\hline Ramas en copo & & $X$ & $X$ \\
\hline Crecimiento anormal de brotes apicales & $X$ & $X$ & $X$ \\
\hline Escobas de bruja & & & $X$ \\
\hline Amarillamiento & & & $X$ \\
\hline "Hojillas" & $\times$ & & \\
\hline Tejido vascular necrosado & $\times$ & $14 / 15$ & $17 / 20$ \\
\hline Prevalencia & $12 / 33$ & $93 \%$ & $85 \%$ \\
\hline
\end{tabular}

${ }^{1}$ Prevalencia estimada como el número de árboles con más de tres síntomas sobre el total de árboles visitados en diciembre de 2013 , en 6 localidades diferentes de Bogotá.
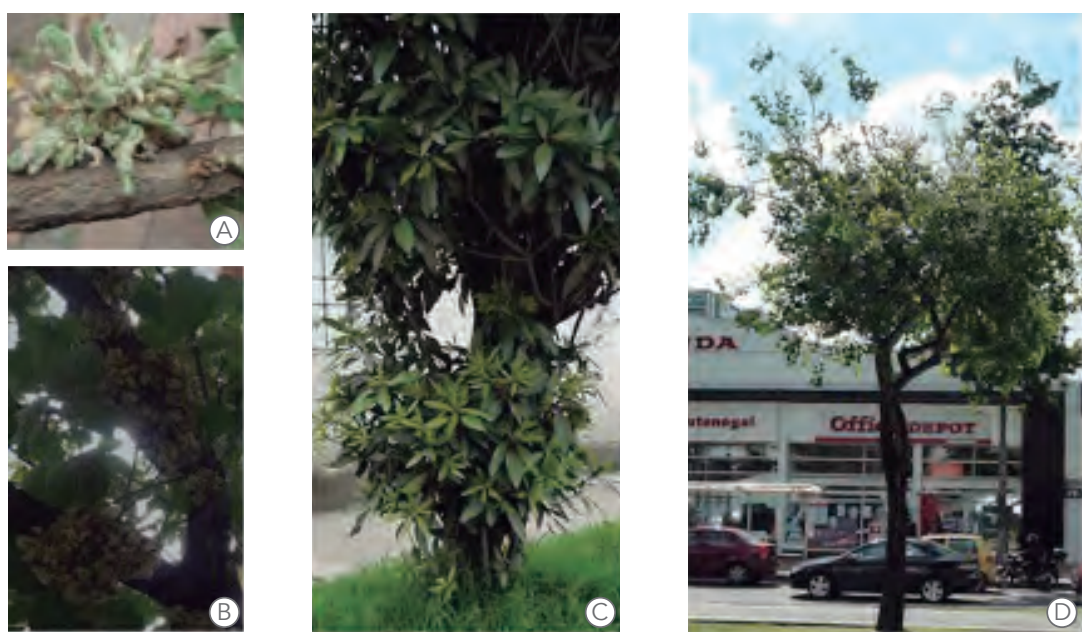

Figura 2. Síntomas de fitoplasmosis en las tres especies de árboles estudiadas. A detalle de "hojillas" en Croton spp., B. "hojillas cubriendo las ramas de Croton spp., C. Rebrote epicórmico en la base del tronco de P. undulatum, y D. P. nigra con deformación de la corona causada por elongación anormal de algunos brotes apicales. 
Los árboles P. undulatum y P. nigra presentaron coronas con arquitectura atípica, generalmente causada por la presencia de elongaciones anormalmente largas de los brotes apicales, ramas en copo (ramas con entrenudos cortos que hacen que las hojas tengan la apariencia de estar muy juntas) o escobas de bruja (generación de muchas ramas a partir de un único punto de crecimiento) y amarillamiento, que en cada especie toma una forma diferente. Otro síntoma muy evidente fueron los brotes epicórmicos (brotes con hojas que emergen del tronco o de ramas viejas en lugares donde no debería haber brotación). Por otro lado, los síntomas en Croton spp. son un poco diferentes pues no se observaron deformaciones marcadas de la corona, pero si "hojillas" (estructuras similares a hojas pequeñas, engrosadas, con desarrollo excesivo de tricomas que cubren los troncos y ramas de los árboles afectados), machas necróticas del tejido vascular y brotes epicórmicos en tronco y ramas (Figura 2).

En este trabajo se realizó una estimación preliminar de la prevalencia de fitoplasmosis en las tres especies en estudio en Bogotá. Se visitaron 6 zonas de las ciudad donde se registró la presencia o

Tabla 2. Resumen de resultados de PCR anidada y secuencias reportadas para el grupo 16SrVII

\begin{tabular}{|c|c|c|c|c|c|c|}
\hline Especie & & $\begin{array}{l}\text { R16F2n/ } \\
\text { R16R2 }\end{array}$ & fU5/rU3 & $\begin{array}{l}\text { PhyRNA3.3/ } \\
\text { PhyRNA2.6 }\end{array}$ & $\begin{array}{c}\text { Grupo } \\
\text { 16SrRNA } \\
\text { RFLP } 1\end{array}$ & $\begin{array}{l}\text { Número de } \\
\text { accesión }^{2} \text { de } \\
\text { secuencias del } \\
\text { grupo } 16 \mathrm{SrVII}\end{array}$ \\
\hline \multirow{6}{*}{ Croton spp. } & CB1 & + & - & - & \multirow{6}{*}{ I, VII, I / VII } & \multirow{6}{*}{ HG764348 } \\
\hline & CB2 & + & + & + & & \\
\hline & CB3 & + & + & - & & \\
\hline & CB4 & - & - & - & & \\
\hline & CB5 & + & - & - & & \\
\hline & CB6 & - & - & - & & \\
\hline \multirow{4}{*}{ P. nigra } & PN1 & + & - & + & \multirow{4}{*}{ I, I / VII } & \multirow{4}{*}{ HG764355 } \\
\hline & PN2 & - & - & - & & \\
\hline & PN3 & - & - & - & & \\
\hline & PN4 & - & + & - & & \\
\hline \multirow{5}{*}{ P. undulatum } & PU1 & - & - & - & \multirow{5}{*}{ I, VII } & \\
\hline & PU2 & + & - & - & & \\
\hline & PU3 & + & - & - & & \\
\hline & PU4 & - & - & - & & \\
\hline & PU5 & - & - & - & & \\
\hline
\end{tabular}

El signo (+) indica bandas del tamaño esperado obtenidas por PCR anidada. El signo (-) ausencia de banda en el gel de electroforesis.

${ }^{1}$ El grupo 16SrRNA de fitoplasmas se estableció por RFLP y/o secuenciación. El símbolo (/) denota los casos en los que hay evidencia de infecciones mixtas en el mismo árbol.

${ }^{2}$ Número de Accesión a GenBank 
Tabla 3. Identidad de secuencias de fitoplasmas del grupo 16SrVII de Bogotá comparado con una secuencia de referencia de Fraxinus de Norte América

\begin{tabular}{|c|c|c|c|c|c|c|c|}
\hline Especie & $\begin{array}{l}\text { Secuencias } \\
\text { colombianas }\end{array}$ & $\begin{array}{l}\text { Puntaje } \\
\text { máximo }\end{array}$ & $\begin{array}{c}\text { Puntaje } \\
\text { total }\end{array}$ & $\begin{array}{l}\text { Cobertura } \\
\text { de la } \\
\text { secuencia }\end{array}$ & Valor E & Identidad & $\begin{array}{c}\text { Secuencia } \\
16 \text { SrVII } \\
\text { de Norte } \\
\text { América }\end{array}$ \\
\hline Croton spp & HG764348 & 1003 & 1003 & $100 \%$ & 0.0 & $100 \%$ & \\
\hline P. nigra & HG764355 & 981 & 981 & $99 \%$ & 0.0 & $99 \%$ & JQ868445.1 \\
\hline F. uhdei & AY687786* & 1698 & 1698 & $100 \%$ & 0.0 & $100 \%$ & \\
\hline
\end{tabular}

*Secuencia obtenida en un trabajo anterior

ausencia de síntomas en árboles escogidos al azar. La prevalencia encontrada fue del 36\% para Croton spp., $93 \%$ para $P$. nigra y $85 \%$ para $P$. undulatum.

\section{Detección de fitoplasmas}

Las muestras fueron evaluadas por PCR anidada con P1A/P7A seguido por R16F2n/R16R2. En algunos casos cuando se obtuvieron amplificaciones inespecíficas o las bandas no fueron visibles por electroforesis, se realizó una reacción subsiguiente con fU3/rU5 y/o con PhyRNA3.3/PhyRNA2.6 (Tabla 2). En todos los casos en los que se utilizaron tres pares de iniciadores consecutivos la presencia de fitoplasmas se confirmó por secuenciación y/o RFLP de la región R16F2n/R16R2. En todas las especies evaluadas se detectó por PCR anidada la presencia de fitoplasmas (Tabla 2, Figura 3 A).

Para determinar los grupos a los que pertenecían los fitoplasmas detectados, los amplicones obtenidos con los iniciadores R16F2n/R16R2 se analizaron por RFLP (Figuras 3B y 3C) y por secuenciación; además amplicones obtenidos con otras combinaciones de iniciadores se enviaron a secuenciar (Tabla 2). La presencia de 'Ca. Phytoplasma asteris' (16Srl) había sido reportada anteriormente por secuenciación para todas las especies,

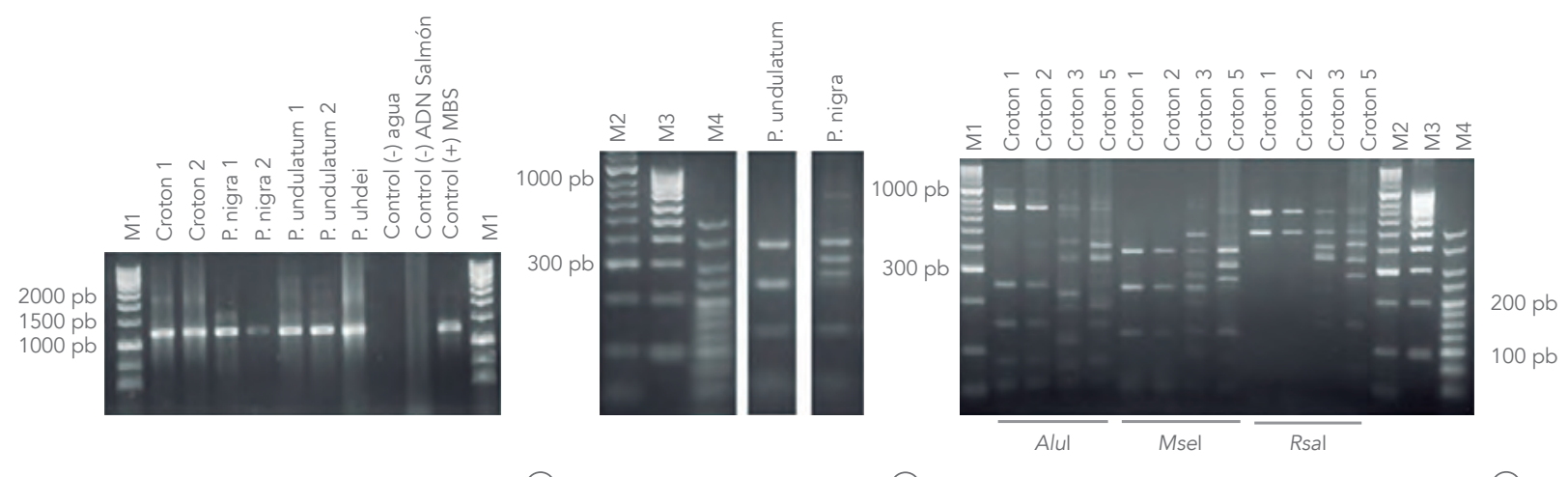

(A)

(B)

Figura 3. Detección molecular de fitoplasmas en árboles de Bogotá. A. PCR anidada de muestras de Croton spp., P. undulatum y P. nigra con inciadores P1A/P7A seguido por R16F2n/R16R2. B. Ejemplo de patrones de RFLP del amplicón R16F2n/R16R2 de P.nigra y P. undulatum, digerido con Mse I. C. Cambiar la letra. Patrones de RFLP de amplicones R16F2n/R16R2 de cuatro individuos de Croton spp. obtenidos con Alul, Msel y Rsal. 


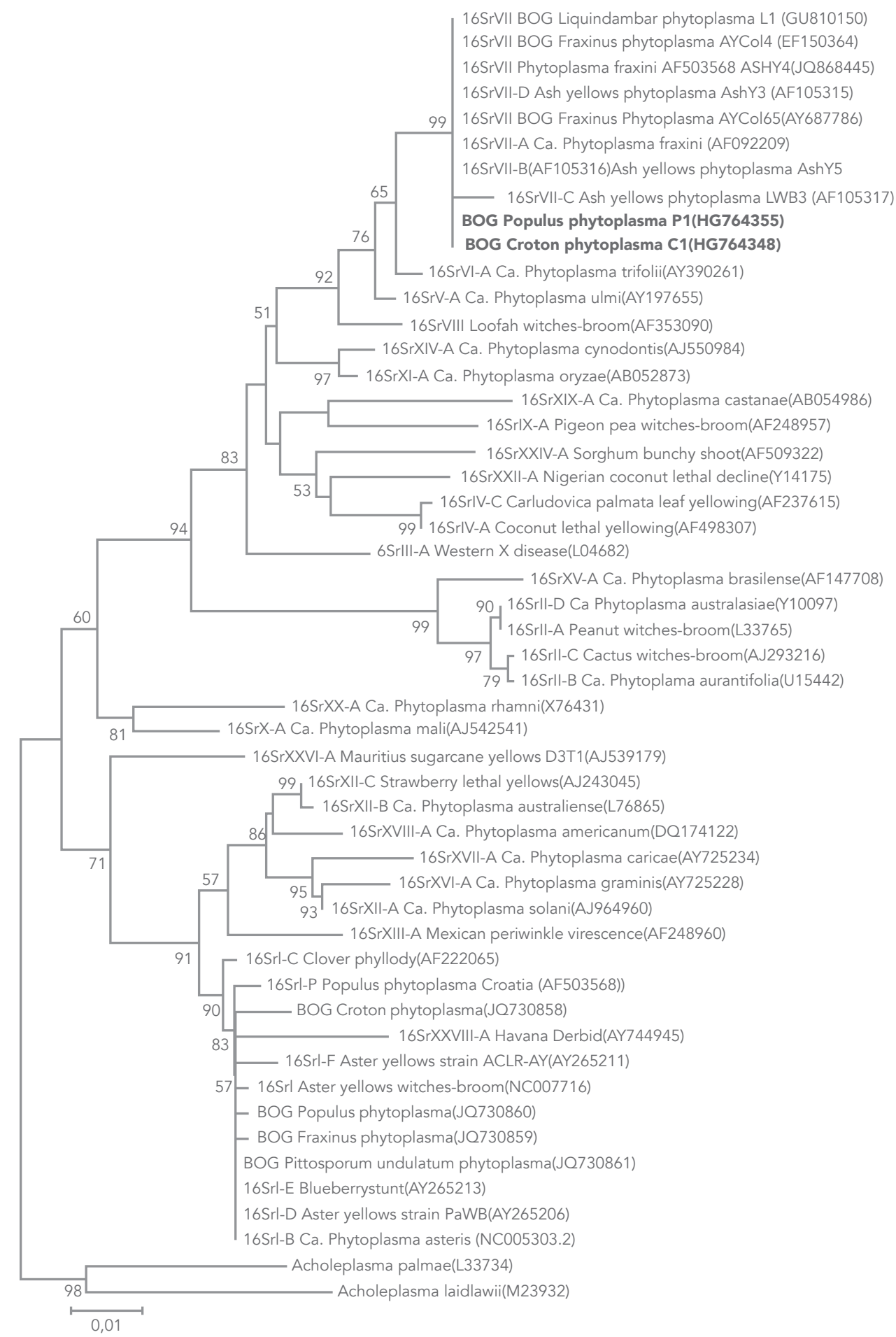

Figura 4. Dendograma construido por el método Neighbor Joining (Bootstrap 1000) de la región 16SrRNA (505 posiciones) de fitoplasmas encontrados en P. nigra y Croton spp. de Bogotá. En negrilla se señalan las secuencias de fitoplasmas reportadas en este trabajo. 
pero en este caso se obtuvo evidencia por RFLP por la presencia de patrones de restricción específicos (Figura 3B y 3C). Además, se detectó la presencia de 'Ca. Phytoplasma fraxini' (16SrVII) en muestras de las tres especies por RFLP y en Croton spp. y $P$. nigra por secuenciación. Un ejemplo es el gel presentado en la Figura 3B donde se observó la presencia de fitoplasmas del grupo $16 \mathrm{SrVII}$ en muestras $P$. undulatum y de los grupos $16 \mathrm{Srl}$ y $16 \mathrm{SrVII}$ simultáneamente en $P$. nigra. El gel que se presenta en la figura 3 C presenta los resultados obtenidos en cuatro muestras de Croton spp. diferentes, digeridas con tres enzimas de restricción. Las muestras 1 y 2 estaban infectadas con el grupo $16 \mathrm{SrVII}$ y la muestra 5 con $16 \mathrm{Srl}$ y $16 \mathrm{SrVII}$ simultáneamente. El caso de la muestra Croton 3 es más complejo porque se encontró infectada con $16 \mathrm{SrVII}$ pero además se observaron otras bandas inespecíficas que podrían corresponder a otro grupo de fitoplasmas o la amplificación de otra bacteria.

Las secuencias obtenidas a partir de las diferentes especies de árboles se presentan en la Tabla 2. Cuando las secuencias obtenidas en Croton spp. y P. nigra fueron comparadas mediante BLAST con secuencias de NCBI se encontró que mostraban una identidad de más del 99\% con secuencias del subgrupo 16SrVIIA de Fraxinus de Norte América, así como con una secuencia anteriormente obtenida de F. uhdei de Bogotá (Tabla 3). Los coeficientes de similitud de RFLP de secuencias de 505 nucleótidos fueron del 100\% al comparar una secuencia de referencia de Fraxinus de Norte América (JQ868445.1) con las dos secuencias de fitoplasmas de Croton spp. (HG764348) y P. nigra (HG764355) reportadas en este trabajo. El dendograma construido incluyendo estas confirma la altísima identidad de los aislados 16SrVII-A de Bogotá y de Norte América (Figura 4). En resumen, la presencia de fitoplasmas de grupo 16SrVII fue demostrada o por secuenciación o por RFLP en individuos de Croton spp. P. undulatum y $P$. nigra.

\section{DISCUSIÓN}

El presente trabajo presenta evidencia de la existencia de fitoplasmas Ca. Phytoplasma fraxini' subgrupo 16SrVII-A en Bogotá, infectando árboles de Croton spp., P. nigra y $P$. undulatum obtenida por PCR anidada (Figura 3 A), secuenciación (Tablas 2 y 3, Figura 4) y RFLP (Figuras 3B y 3C) en los mismos árboles en los cuales en un trabajo anterior se demostró la presencia de fitoplasmas del grupo 16Srl (Perilla et al., 2012, Franco-Lara, 2013). Los resultados presentados en este trabajo indican que frecuentemente los fitoplasmas del grupo $16 \mathrm{SrVII}$ se encuentran en infecciones mixtas con fitoplasmas del grupo 16 Srl en los árboles evaluados.

Una primera fuente de evidencia que sugiere la presencia de fitoplasmas en Croton spp., P. nigra y

Los resultados presentados en este trabajo indican que frecuentemente los fitoplasmas del grupo 16SrVII se encuentran en infecciones mixtas con fitoplasmas del grupo $16 \mathrm{Srl}$ en los árboles evaluados. 


\section{En el caso de las infecciones asociadas a fitoplasmas, se observa que en la misma planta hospedera diferentes grupos de fitoplasmas produzcan síntomas similares. Es más, plantas con infecciones mixtas no parecen tener síntomas diferentes o más agresivos que plantas infectadas con un solo fitoplasma.}

P. undulatum provino de la observación de los síntomas en individuos de estas especies. En P. nigra y $P$. undulatum, se observaron deformaciones de la corona debidas a la presencia de ramas en copo, elongación anormal de brotes apicales, escobas de bruja, así como amarillamiento y rebrotación epicórmica. En los árboles de Croton spp. no se observaron deformaciones de la corona, pero sí la presencia de "hojillas", estructuras atípicas en forma de hoja que recubren ramas y tronco, brotes epicórmicos, crecimiento anormal de brotes apicales y necrosis del tejido vascular. Síntomas como estos han sido descritos para árboles ornamentales de otras especies (Sinclair y Griffiths, 1994; Sinclair et al., 1996; Boa, 2003; referencia web 1, referencia web 2 y referencia web 3). Los síntomas asociados a fitoplasmas en plantas, son atribuidos por una parte al taponamiento del floema y por otra parte al desarreglo de los reguladores de crecimiento (Lee et al., 2000; Christensen et al., 2005 Bertaccini y Duduk, 2009). Los mecanismos por los cuales los fitoplasmas afectan la morfología de las plantas, están en estudio. Un caso caracterizado es en la cepa OY de "Ca. P. asteris" donde se evaluó la función de una proteína fitoplásmica de 4.5 kDa (TENGU) y se encontró que es capaz de suprimir la respuesta de la planta a las auxinas, lo que induce morfología anormal cómo escobas de bruja y enanismo (Hoshi et al., 2009).

En el caso de las infecciones asociadas a fitoplasmas, se observa que en la misma planta hospedera diferentes grupos de fitoplasmas produzcan síntomas similares. Es más, plantas con infecciones mixtas no parecen tener síntomas diferentes o más agresivos que plantas infectadas con un solo fitoplasma (Gibb et al., 1999; Constable et al., 2002; De La Rue et al, 2001; Lee et al., 2006). En este caso, los árboles afectados estaban infectados por un complejo de fitoplasmas de los grupos $16 \mathrm{Srl}$ y $16 \mathrm{SrVII}$ pero la contribución de cada grupo individual de fitoplasmas en la generación de los síntomas y los efectos para la transmisión por los insectos vectores, evolución y adaptación a nuevos hospederos es deconocida.

Las secuencias obtenidas en este trabajo que provienen de árboles de Croton spp. y de P. nigra pertenecen al subgrupo 16SrVII-A y tienen similitudes superiores al $99 \%$ y coeficientes de identidad por RFLP del 100\% comparadas con secuencias previamente reportadas en F. uhdei de Bogotá y de Fraxinus de Norteamérica (Tabla 3). El urapán F. uhdei es una especie nativa de Centro América, introducida en Bogotá según parece en la década de 1950 y que de hecho, en muchos libros aparece erróneamente identificada como F. chinensis ( $E$. Wallander, (año) comunicación personal, County Administrative Board, Jönköping, Suecia). Desafortunadamente la historia precisa de la importación de los F. uhdei a Bogotá se ha perdido, pero se sugiere que fueron traídos en forma de esquejes de Norte América y no de China como generalmente se cree. Los resultados de este trabajo apoyan 
la idea de que los fitoplasmas del grupo 16SrVII detectados en Colombia vinieron en los F. uhdei importados de Norteamérica, de donde se dispersaron a especies de géneros distintos a Oleáceae, como Croton spp., P. undulatum, P. nigra y Liquidambar styraciflua conquistando nuevos nichos (Franco-Lara et al., 2010).

La dispersión de los fitoplasmas en la naturaleza depende de la capacidad de los insectos vectores para transmitirlos de plantas infectadas a plantas sanas. Hasta hace poco no existían reportes de vectores de fitoplasmas del grupo 16SrVII (Hill y Sinclair, 2000, Feeley et al., 2001). Sin embargo un estudio realizado recientemente por nuestro grupo encontró que dos especies de insectos de la familia CicadeIlidae, géneros Exitianus y Amplicephalus eran capaces de transmitir experimentalmente fitoplasmas del grupo 16SrVII a plantas de fríjol (Perilla, 2013; resultados en publicación). Por otro lado, un estudio anterior demostró la inoculación experimental de fitoplasmas de F. uhdei a plantas herbáceas como Apium graveolens (Apiaceae), Nicotiana tabacum y N. debneyi (Solanaceae), colocando las plantas herbáceas en las ramas del árbol y permitiendo la visita no controlada de insectos. Además de determinar que las herbáceas eran susceptibles a fitoplasmas, se demostró que los insectos vectores eran capaces de alimentarse también de otras plantas, presentando la primera evidencia de la existencia de insectos vectores polífagos (Perilla et al., 2010).

En su conjunto, estos resultados sugieren que el grupo $16 \mathrm{SrVII}$ no es un patógeno exclusivo de la familia Oleaceae y que en presencia de un vector apropiado es capaz de infectar otras familias de plantas. Las observaciones hechas por nuestro grupo y por el Jardín Botánico José Celestino Mutis (J. A. Castro (2012), comunicación personal) indican que por lo menos para Croton spp. y para P. undulatum, los síntomas asociados a fitoplasmosis son recientes, no observados antes de 2007. Entonces, las fitoplasmosis en estos árboles puedan ser consideradas enfermedades emergentes, que no existían hasta hace pocos años. En la actualidad no existe una explicación a la reciente aparición de estas nuevas enfermedades en la ciudad, pero estos resultados ponen de manifiesto la grave situación fitosanitaria de los árboles de Bogotá y la necesidad de estudiar la epidemiología de estas enfermedades para disminuir su impacto y la creciente dispersión a otras especies ornamentales de interés comercial en la ciudad y sus alrededores. Hasta donde sabemos, este es el primer reporte de infecciones mixtas en las que participa el grupo 16SrVII; la existencia de estas infecciones indica que en Bogotá existen insectos vectores para los dos grupos de fitoplasmas lo que implica un alto riesgo de infección a otras especies de plantas.

\section{AGRADECIMIENTOS}

Las autoras agradecen al José Arnulfo Castro del Jardín Botánico de Bogotá José Celestino Mutis por compartir sus observaciones acerca de los síntomas presentes en árboles de Croton spp, de Bogotá, así como a la Dra Assunta Bertaccini y al Dr Nigel Harrison por habernos donado ADN control para los ensayos de PCR anidada. También a la Universidad Militar Nueva Granada por la financiación del proyecto CIAS 550 . 


\section{BIBLIOGRAFÍA}

1. Alma A., Davis R.E., Vibio M., Danielli A., Bosco D., Arzone A. y Bertaccini A. 1996. Mixed infection of grapevines in northern Italy by phytoplasmas including 16S rRNA RFLP subgroup $16 \mathrm{Srl}-\mathrm{B}$ strains previously unreported in this host. Plant Disease 80, 418-421

2. Altschul S.F., Gish W, Miller W, Myers E.W. y Lipman D.J. 1990. Basic local alignment search tool. Journal of Molecular Biology 215,403-410.

3. Arismendi N, González F, Zamorano A., Yrade N., Pino A.M. y Fiore N. 2011. Molecular identification of "Candidatus Phytoplasma fraxini' in murta and peony in Chile. Bulletin of Insectology 64, S95-S96.

4. Barros T.S.L., Davis R.E., Resendeye R.O. y DaIly E.L. 2002. Erigeron witches' broom phytoplasma Yellows Phytoplasma Group. Plant Disease 86, 1142-1148.

5. Bertaccini A. y Duduk B. 2009. Phytoplasma y phytoplasma diseases: a review of recent research. Phytopathologia Mediterranea 48, 355-378.

6. Boa E. 2003. An illustrated guide to the state of health of trees Recognition y interpretation of symptoms y damage. CABI Bioscience.

7. Bruni R., Pellati F., Bellardi M.G., Benvenuti S., Paltrinieri S., Bertaccini A., Bianchi A. 2005. Herbal drug quality y phytochemical composition of Hypericum perforatum L. affected by ash yellows phytoplasma infection. Journal of Agricultural y Food Chemistry 53, 964-968.
8. Conci L., Meneguzzi N., Galdeano E., Torres L., Nome C. y Nome S. 2005. Detection y molecular characterisation of an alfalfa phytoplasma in Argentina that represents a new subgroup in the $16 \mathrm{~S}$ rDNA ash yellows group ('Candidatus Phytoplasma fraxini'). European Journal of Plant Pathology 113,255-265.

9. Constable, F.E., Whiting, J.R., Jones, J., Gibb K.S. and Symons R.H. 2002 A new grapevine yellows phytoplasma from the Buckland Valley of Victoria, Australia. Vitis 41, 147-154.

10. Christensen N.M., Axelsen K.B., Nicolaisen M. y Schulz A. 2005. Phytoplasmas and their interactions with hosts. Trends in Plant Science 10, 526-535.

11. Contaldo N., Bertaccini A., Paltrinieri S., Windsor H. M. y Windsor G. D. 2012. Axenic culture of plant pathogenic phytoplasmas. Phytopathologia Mediterranea 51, 607-617

12. De la Rue, S., Padovan, A. and Gibb, K. 2001. Stylosanthes is a Host for Several Phytoplasmas, One of which Shows Unique 16S-23S Intergenic Spacer Region Heterogeneity. Journal of Phytopathology 149, 613-619.

13. Feeley C.H., Hart E.R., Thompson J.R. Y Harrington T.C. 2001. Occurrence, associated symptoms y potential insect vectors of the Ash yellows phytoplasma in lowa, U.S. Journal of Arboriculture 27, 331-340.

14. Filgueira JJ, Franco-Lara L., Salcedo JE. Gaitan SL, Boa ER, 2004. Urapán (Fraxinus udhei) dieback a new disease associated with a 
phytoplasma in Colombia. The British Society for Plant Pathology. New Disease Reports 9, 6.

15. Franco-Lara L. y Filgueira J.J. 2005, Síntomas de decaimiento del Urapán (Fraxinus sp.) en Colombia. Fitopatología Colombiana 29, 32-38.

16. Franco-Lara L., Contaldo N., Martínez C., Calari A., Paltrinieri S., Duduk B., Bertaccini A. 2010. Complex phytoplasma infection in declining liquidambar trees in Colombia. Abstract Book 18th Congress International Organization for Mycoplasmology, Chianciano Terme Italy July 2010.

17. Franco-Lara L. 2013. Identification of phytoplasmas infecting native and introduced tree species in Bogota, Colombia. Phytopathology 103, S2.46.

18. Gibb, K.S., Constable, F.E., Moran, J.R. and Padovan A.C. 1999. Phytoplasmas in Australian grapevines - detection, differentiation and associated diseases. Vitis 38, 107-114.

19. Griffiths H.M., Boa E.R. y Filgueira J.J. 2001. Ash yellows disease of Fraxinus chinensis in Colombia. Phytopathology 91, S32-S33

20. Griffiths H.M., Sinclair W.A., Smart D.C. y DAVIS R.E. 1999. The phytoplasma associated with ash yellows y lilac witches'-broom: 'Candidatus Phytoplasma Fraxini'. International Journal of Systematic Bacteriology 49, 1605-1614.

21. Gundersen D.E., Lee I.M, REHNER SA, DAVIS, RE y KINGSBURY DT. 1994. Phylogeny of mycoplasmalike organisms (phytoplasmas): a basis for their classification. Journal of Bacteriology 176, 5244-5254.
22. Gundersen D.E. y Lee I.M. 1996. Ultrasensitive detection of phytoplasmas by nested-PCR assays using two universal initiador pairs. Phytopathology Mediterranea 35, 144-151.

23. Hill G.T. y Sinclair W.A. 2000. Taxa of leafhoppers carrying phytoplasmas at sites of Ash Yellows occurrence in New York State. Plant Disease 84,134-138.

24. Hogenhout S.A., Oshima K., Ammar E.D., Kakizawa S., Kingdom H.N. y Namba S. 2008. Phytoplasmas: bacteria that manipulate plants y insects. Molecular Plant Pathology 9, 403-423.

25. Hoshi A., Oshima K., Kakizawa S., Ishiia Y., Ozeki J., Hashimoto M., Komatsu K., Kagiwada S., Yamaji Y. y Namba S. 2009. A unique virulence factor for proliferation and dwarfism in plants identified from a phytopathogenic bacterium. PNAS 106, 6416-6421.

26. IRPCM Phytoplasma/Spiroplasma Working Team-Phytoplasma, 2004. 'Candidatus Phytoplasma', a taxon for the wall-less, non-helical prokaryotes that colonise plant phloem y insects. International Journal of Systematic and Evolutionary Microbiology 54, 1243-1255.

27. Lee, I.M., Bottner,K.D., Secor,G. y Rivera-Varas. V. 2006. 'Candidatus Phytoplasma americanum', a phytoplasma associated with a potato purple top wilt disease complex. International Journal of Systematic and Evolutionary Microbiology 56, 1593-1597.

28. Lee I-M., Davis R.E. y Gundersen-Rindal D.E. 2000. Phytoplasma: Phytopathogenic 
Mollicutes. Annual Review Microbiology 54, 211-55.

29. Lee I.M., Danielli A., Bertaccini A., Vibio M. y Bartoszyk I.M. 1996. Multiple phytoplasmas detected in two species of Homoptera feeding on pear trees with decline symptoms. International Organization Mycoplasmology Letter 4: 199.

30. Lee I-M., Gundersen D.E., Hammond R.W. y Davis R.E. 1994. Use of mycoplasmalike organism (MLO) group-specific oligo- nucleotide primers for nested-PCR assays to detect mixed-MLO infections in a single host plant. Phytopathology 84, 559-566.

31. Lee I.M., Gundersen-Rindal D.E., Davis R.E. y Bartoszyk I.M. 1998. Revised classification scheme of phytoplasmas based on RFLP analysis of $16 \mathrm{~S}$ rRNA y ribosomal protein gene sequences. International Journal of Systematic Bacteriology 48, 1153-1169.

32. Lee I.M., Gundersen-Rindal D.E., Davis R.E., Bottner K.D., Marcone C. y Seemuller E. 2004. 'Candidatus Phytoplasma asteris', a novel phytoplasma taxon associated with aster yellows y related diseases. International Journal of Systematic y Evolutionary Microbiology 54, 1037-1048

33. Lee I.M., Martini M., Bottner K.D., Dane R.A., Black M.C. y Troxclair N. 2003. Ecological implications from a molecular analysis of phytoplasmas involved in an Aster Yellows epidemic in various crops in Texas. Phytopathology 93, 1368-1377.
34. Lee I.M., Zhao Y. y Bottner K.D. 2006. SecY gene sequence analysis for finer differentiation of diverse strains in the aster yellows phytoplasma group. Molecular and Cellular Probes 20, 87-91.

35. Leyva-López N.E., Ochoa-Sánchez J.C., LealKlevezas D.S. y Martínez-Soriano J.P. 2002. Multiple phytoplasmas associated with potato diseases in Mexico. Canadian Journal of Microbiology 48, 1062-1068.

36. Longone V., González F., Zamorano A., Pino A.M., Araya J., Díaz V., Paltrinieri S., Calari A., Bertaccini A., Picciau L., Alma A. y Fiore N. 2011. Epidemiological aspects of phytoplasmas in Chilean grapevines. Bulletin of Insectology 64, S91-S92.

37. Martini M., Lee I.M., Bottner K.D., Zhao Y., Botti S., Bertaccini A., Harrison N.A, Carraro L., Marcone C., Khan J. y Osler R. 2007. Ribosomal protein gene-based phylogeny for finer differentiation and classification of phytoplasmas. International Journal of Systematic y Evolutionary Microbiology 57, 2037-2051.

38. Nejat N., Vadamalai G., Davis R.E., Harrison N.A., Sijam K., Dickinson M., Abdullah S.N. y Zhao Y. 2013. 'Candidatus Phytoplasma malaysianum', a novel taxon associated with virescence y phyllody of Madagascar periwinkle (Catharanthus roseus). International Journal Systematic Evolutionary Microbiology 63, 540-548.

39. Oxelman B., Lide'n M. y Bergund D. 1997. Chloroplast rps16 intron phylogeny of the tribe 
Sileneae (Caryophyllaceae). Plant Systematic Evolution 206, 393-410.

40. Perilla L.M. 2013. Determinación de la capacidad de transmisión de fitoplasmas en dos morfoespecies de la familia Cicadellidae (Hemiptera: Auchenorryncha) de Bogotá D.C. Tesis para optar al título de Magister en Bioquímica, Universidad Nacional de Colombia, Sede Bogotá.

41. Perilla-Henao L.M.,Dickinson M. y Franco-Lara L, 2012. First report of 'Candidatus Phytoplasma asteris' affecting woody hosts (Fraxinus uhdei, Populus nigra, Pittosporum undulatum y Croton spp.) in Colombia. Plant Disease 96, 1,372.2 - 1,372.2.

42. Perilla L.M., Gutiérrez C.G., Filgueira J.J. y Franco-Lara L. 2010. Inoculación experimental de tres especies hospederas de fitoplasmas en Bogotá, Colombia. Revista Facultad de Ciencias 6, 198-213.

43. Prince J.P., Davis R.E., Wolf T.K., Lee I-L, Mogen B.D., Dally E.L., Bertaccini A. y Barba M. 1993. Molecular detection of diverse mycoplasmalike organisms (MLOs) associates with grapevine yellows $y$ their classification with Aster Yellows, X-Disease, y Elm Yellows MLOs. Phytopathology 83, 1130-1137.

44. Sears B.B. y Kirkpatrick B.C. 1994. Unveiling the evolutionary relationships of plant pathogenic mycoplasmalike organisms. ASM News 60, 307-312.
45. Seemüller E., Marcone C., Lauer U., Ragozzino A. y Göschl M. 1998. Current status of molecular classification of the phytoplasmas. Journal of Plant Pathology 80: 3-26.

46. Seemüller E., Schneider B. y Maürer R. 1994. Phylogenetic classification of phytopathogenic mollicutes by sequence analysis of $16 \mathrm{~S}$ ribosomal DNA. International Journal Systematic Bacteriology 44, 440-446.

47. Smart C.D., Schneider B., Blomquist C.L., Guerra L.J., Harrison N.A., Ahrens U., Lorenz K.H., Seemüller E. y Kirkpatrick B.C. 1996. Phytoplasma-specific PCR primers based on sequences of $16 \mathrm{~S}$ rRNA spacer region. Applied Environmental Microbiology 62, 2988-3033.

48. Sinclair W. A. y Griffiths H. M. 1994. Ash yellows its relationship to dieback y decline of ash. Annual Review of Phytopathology 32:49-60

49. Sinclair W. A., Griffiths H.M. y Davis R.E. 1996. Ash Yellows y Lilac Witches'-Broom: phytoplasmal diseases of concern in forestry y horticulture. Plant disease 80, 468-475.

50. Tamura K., Peterson D., Peterson N., Stecher G., Nei M. y Kumar S. 2011. MEGA5: Molecular Evolutionary Genetics Analysis using Maximum Likelihood, Evolutionary Distance, y Maximum Parsimony Methods. Molecular Biology y Evolution 28, 2731-2739.

51. Wei W., Davis R.E., Lee I-M y Zhao Y. 2007. Computer-simulated RFLP analysis of $16 \mathrm{~S}$ rRNA genes: identification of ten new phytoplasma 
groups. International Journal of Systematic and Evolutionary Microbiology 57, 1855-1867.

52. Weintraub P.G. y Beanland L. 2006. Insect Vectors of Phytoplasmas. Annual Review Entomology 51, 91-111.

53. Zhao Y., Wei W., Davis R.E. y Lee I-M. 2010. Recent advances in 16S rRNA gene-based phytoplasma differentiation, classification y taxonomy. In: Phytoplasmas: Genomes, Plant Hosts y Vectors. Eds. PG Wintraub y P. Jones. CABI International 2010.

54. Zhao Y., Wei W., Lee I-M., Shao J., Suo X. y Davis R.E. 2009. Construction of an interactive online phytoplasma classification tool, iPhyClassifier, $y$ its application in analysis of the peach $\mathrm{X}$-disease phytoplasma group (16SrIII). International Journal of Systematic y Evolutionary Microbiology 59, 2582-2593.

55. Zunnoon-Khan S., Arocha-Rosete Y., Scott J., Crosby W., Bertaccini A. y Michelutti R, 2010. First report of 'Candidatus Phytoplasma fraxini' (group 16SrVII phytoplasma) associated with a peach disease in Canada. New Disease Reports 21, 20.

\section{REFERENCIAS WEB}

1. Davis R.E., Shao J., Lee I.-M., Wei W. y Zhao Y. 2009. Phytoplasma Resource Center. http:// plantpathology.ba.ars.usda.gov/phytoplasma. html Consulta Diciembre 2013.
2. Bertaccini A., Nicolaisen M., Duduk B., Weintraub P., Jarausch W., Hogenhout S., Dickinson M. y Verbeek M. 2009. COST action FA 0807: Integrated Management of Phytoplasma Epidemics in Different Crop Systems. http:// www.costphytoplasma.ipwgnet.org/ Consulta Diciembre 2013.

3. Hort-answers. University of Illinois Extension. http://urbanext.illinois.edu/hortanswers/browseproblemsbytype.cfm?PathogenTypelD $=8$. Consulta Diciembre 2013 